\title{
AS PRÁTICAS DE PARTICIPAÇÃO POPULAR NA ESTRATÉGIA DE SAÚDE DA FAMÍLIA (ESF): FATORES POTENCIALIZADORES E LIMITANTES
}

\author{
THE COMMUNITY PARTICIPATIVE PRACTICES IN STRATEGY \\ IN HEALTH OF THE FAMILY (SHF): STIMULANT AND LIMITER FACTORS \\ LAS PRÁCTICAS DE PARTICIPACIÓN POPULAR EN LA ESTRATEGIA \\ DE SALUD DA FAMILIA (ESF): FACTORES ESTIMULANTES E LIMÍTROFES
}

Fátima Regina Reiser dos Santos* Àgueda Wendhausen**

RESUMO: Ainda que prevista em lei, a participação da população não está incorporada em nosso cotidiano de assistência à saúde e sua importância, muitas vezes, foge da percepção da maioria dos profissionais de saúde e da própria comunidade. Este artigo tem o propósito de oferecer subsídios para as práticas participativas em saúde da família, através da reflexão sobre nossas experiências em uma equipe de saúde da família com grupos organizados da comunidade a partir do que levantamos os fatores limitantes e potencializadores dessas práticas. Espera-se que esta reflexão possa contribuir para a compreensão e análise das vivências de participação, especialmente a verificada nos conselhos de saúde, que vêm se disseminando pelo país, envolvendo a comunidade na discussão das metas de saúde. Desta forma a integração favorecida pela inserção da comunidade na definição das ações de saúde rompe as barreiras que limitam o processo de participação.

PALAVRAS-CHAVE: Educação em saúde; Participação comunitária; Saúde da família

\footnotetext{
Enfermeira, coordenadora de Unidade de Saúde da Família (PSF) Prefeitura Municipal de Blumenau, mestranda em Saúde - Saúde da Família (UNIVALI). Fone: (47)324-0748 e-mail: fatimareiser@brturbo.com

** Enfermeira, Coordenadora do Mestrado em Saúde (UNIVALI), Doutora em enfermagem (UFSC). Itajaí - SC. Fone: (47) 344-1243 e-mail: aguejor@milnegocios.com.br
}

\section{INTRODUÇÃO}

A origem das formas de envolvimento dos cidadãos no processo político, vem se dando desde o final dos anos 60 a partir da desilusão com as instituições políticas, durante os anos 70 , com o crescimento dos novos movimentos sociais (Revolução de Maio) e ainda pela crise econômica mundial. Neste contexto, os governos promoveram a criação de diferentes formas de participação: os conservadores implementaram políticas em torno das respostas dos serviços às demandas dos participantes (consumidores), já os sociaisdemocratas enfatizavam a necessidade de reforma através de estratégias não centradas no mercado(1).

Na década de 70, no Brasil, profissionais de saúde questionavam o modelo de atenção à saúde, centrado na assistência curativa, individual e hospitalar. Iniciando um processo de reformulação das políticas de saúde, denominado de Reforma Sanitária brasileira, propondo um sistema que garantisse a atenção integral, com equidade, universalidade das ações e com a participação popular na definição destas políticas de saúde.

Com a Conferência de Alma Ata em 1977, houve uma contribuição significativa para consolidar as políticas de participação popular, descrita na 
Declaração dos Cuidados Primários de Saúde da UNICEF/OMS, assegurando "a saúde como direito do cidadão e dever do estado". Nesta mesma direção, em 1988, na Constituição Federal do mesmo ano, em seu artigo 196, são aprovados artigos relativos à saúde, que garantem políticas de redução de riscos, acesso universal e igualitário as ações e serviços de saúde. Para regulamentar o texto que implantou o SUS, foi criada a Lei Orgânica da Saúde (LOS) n. ${ }^{\circ} 8.080 / 90$. Neste mesmo ano foi editada a lei $8.142 / 90$, assegurando os direitos relativos à participação institucionalizada que haviam sido vetados na Lei Orgânica de Saúde (LOS)(2).

Apesar dos grandes avanços do SUS ainda existem muitos desafios a enfrentar na sua operacionalização. Entretanto, como a implementação do SUS ocorreu em um período de profundas transformações, tanto do ponto de vista econômico, quanto social e demográfico, além de passar por várias crises de financiamento tem início, a partir de 1995/96, um período de reformas. Considera-se que as mudanças no modelo assistencial vêm se operando dentro do SUS principalmente por conta de dois novos programas: o Programa de Agentes Comunitários de Saúde - PACS e Estratégia de Saúde da Família - ESF ou Programa de Saúde da Família - PSF, que são estratégias para a reorganização da atenção primária e consolidação do SUS, atuando além dos muros da Unidade de Saúde, estimulando a participação social.

Acreditamos que a ESF se constitui em uma estratégia de reforma do sistema de saúde, tendo em vista que o programa aponta para mudanças importantes na forma de financiamento do sistema de saúde, nas práticas assistenciais e no processo mesmo de participação popular e descentralização.

O papel da Estratégia de Saúde da Família no avanço das formas organizativas da população é evidente, pois incentiva a organização e institucionalidade dos mecanismos de representação da comunidade, aumentando as possibilidades de participação e controle destas sobre as ações públicas ${ }^{(3)}$.
A participação institucionalizada está prevista através da Lei no 8.142 e a maioria dos municípios brasileiros já criou seus conselhos municipais de saúde, porém em minha prática de profissional de saúde observo que a participação não está incorporada em nosso cotidiano de assistência, ou sequer a percepção de sua importância para o desenvolvimento e direcionamento das ações de saúde. Poderia dizer que muitos não conseguem identificar as formas de participação existentes ou as identificam, mas não sabem como aproveitá-las como instrumento para melhoria e consolidação do SUS.

Entretanto, minha experiência enquanto componente da equipe de saúde da família levou-me, a perceber a importância da construção coletiva baseada nas relações cotidianas entre a comunidade e os serviços de saúde e o papel estratégico do profissional para fomentar estas ações. Procurei, pois, neste artigo, ao refletir sobre minhas práticas participativas e dos que me rodeiam no trabalho que exerço no PSF, identificar os diversos fatores limitantes ou potencializadores, na tentativa de contribuir na fomentação de tais práticas.

\section{A EXPERIÊNCIA DA PARTICIPAÇÃO EM NOSSO COTIDIANO}

Uma estratégia que vem se destacando nos programas nacionais desde a passagem dos anos 80 para os anos 90, é a participação comunitária. Esta vem sendo usada como instrumento e suporte nas decisões, no planejamento de metas, socializando o saber e enfatizando a democratização. Desta forma, tem contribuído muito para a melhoria da qualidade dos serviços oferecidos, pois propicia uma melhor utilização dos recursos locais existentes, estimulando a integração e a co-responsabilidade das populações.

Em minha vivência no Programa de Saúde da Família, área onde atuo há oito anos em duas comunidades diferentes, experienciando realidades e formas de participação, também diferentes, identifiquei que o processo de participação se expressa no 
cotidiano da população e para que a sua concretização seja estimulada, implica em ter compreensão clara sobre ele e sobre a realidade social onde o mesmo se processa.

A participação é definida como uma conquista e não pode ser entendida como algo estático, pois é um processo infindável e em constante mudança. É fundamentalmente produto de conquista, não é fenômeno secundário da política social, mas um de seus eixos fundamentais. Pressupõe envolvimento e presença ${ }^{(4)}$. Acreditando que esta se expressa na realidade dos diversos segmentos da população(5).

Tendo em vista que o PSF é considerado uma estratégia para efetivação do SUS e que este tem como uma de suas diretrizes a Participação Popular, entendo que as equipes de saúde da família podem favorecer, através do preconizado pelo programa, uma maior integração profissional-usuário, estimulando, portanto, o envolvimento da comunidade no planejamento e avaliação das ações de saúde.

Atualmente vivencio tanto a participação individual, quando o usuário se conscientiza e se envolve no processo de cuidado, quanto à participação coletiva, concretizada, dentre outros espaços, nos conselhos locais de saúde. Em nossa realidade o conselho local funciona há um ano e é composto por oito representantes da comunidade e oito profissionais de saúde, lembrando que dentre os profissionais estão os Agentes de Saúde (5) que são moradores da comunidade, mas representam os profissionais neste momento ( $50 \%$ comunidade, $50 \%$ profissionais de saúde).

Através da observação dos envolvidos no processo identifiquei alguns fatores que potencializam e outros que limitam o processo de participação comunitária. A partir daí fui desenvolvendo ações para potencializar a participação e minimizar os fatores limitantes. Desta forma, irei relatar, a seguir, algumas das experiências que contribuíram na identificação destes fatores.

Ao iniciarmos nosso trabalho no PSF, recémformados, com toda a expectativa de colocar em prática nossos conhecimentos e de mudar, inovar a saúde, nos deparamos com o novo e com a nossa inexperiência e a partir daí desenvolvemos nossas atividades, avaliando-as e aprimorando-as. Nas duas unidades em que atuamos a participação aconteceu através do estímulo e envolvimento da equipe do PSF com a comunidade adstrita. Um dos pontos iniciais deste processo se deu com a participação efetiva dos componentes da equipe no cotidiano das pessoas, comparecendo e prestigiando todos os eventos realizados na comunidade, principalmente aqueles que caracterizavam uma conquista para eles, como: inauguração da linha de ônibus nos morros, de creche e de novo espaço físico do sacolão (feira), bem como de outros eventos como as festas de Natal, Dia das Crianças, Ação Comunitária, dentre outros. Nosso envolvimento não se deu apenas através do comparecimento a estes eventos, mas também durante todo o seu preparo, por exemplo: na divulgação, organização e captação de recursos (humanos e financeiros).

A participação social é um ponto chave a ser trabalhado na equipe de saúde da família, considerando os avanços necessários para favorecer os princípios da integralidade, universalidade e eqüidade ${ }^{6}$.

Em nossa experiência observamos que quando a comunidade tomou conhecimento de alguns problemas encontrados na unidade de saúde, relacionados à falta de equipamentos, os quais interferiam na qualidade do atendimento, desenvolveu ações para saná-los em conjunto com a equipe. $O$ processo se deu através da organização de um evento para arrecadar fundos pelas associações de moradores e da promoção de reuniões com gestores, com entrega de documentos, a partir do que as necessidades foram atendidas.

Outra experiência que vale destacar é que anualmente, as equipes de PSF realizam um planejamento das ações de saúde em sua área de abrangência. Após a efetivação do Conselho Local de Saúde, este planejamento passou a ser feito em conjunto com o mesmo. Das necessidades identificadas, priorizou-se a falta de atividades extraescola, o que a comunidade acredita ser o motivo 
para os atos de vandalismo e ingresso dos jovens no mundo das drogas. Com isto definimos ações para sanar o problema, dentre as quais uma pesquisa entre adolescentes e crianças em idade escolar, identificando quais as atividades de maior interesse entre os pesquisados. A atividade mais solicitada foi a computação. Listamos, então, as potencialidades da comunidade, ou seja, o que existia nesta comunidade que poderia contribuir para facilitar o desenvolvimento das ações, de acordo com as necessidades levantadas na pesquisa. Isto fez com que percebessem que na própria localidade existiam recursos, para desenvolvermos tais ações e outros que poderiam se reaproveitados tais como: uma empresa que forneceria computadores e professores para curso, professora de pintura em madeira, professora de tricot e crochê, professor de música (violão, teclado), quadra de futebol e vôlei e espaço físico para desenvolver as atividades. O Conselho Local mobilizou-se, agendou reunião com representantes da Associação de Moradores, que em outro momento haviam cedido duas salas para Unidade Básica de Saúde (UBS), propondo que uma das salas cedidas fosse utilizada para o curso de computação. Tendo em vista que a empresa que faz a doação de computadores só a concretizaria se houvesse um espaço, exclusivo, para tal atividade, decidimos, então, que uma das salas seria usada para computação e ficaríamos apenas com uma, a sala de vacinas.

Esta experiência fez-nos refletir que o fato de cedermos este espaço, que para nós era importante, mas que no momento não era tão prioritário (já que não iria dificultar em nada nossas ações), foi muito importante para a conquista da confiança destas pessoas. Com isto demonstramos que as necessidades deles também são importantes para nós e que nós estávamos nos empenhamos para atendê-los. Ao abrirmos mão deste espaço em prol da comunidade colaboramos para potencializar a iniciativa da comunidade para resolver seus problemas e conseqüentemente a deixamos mais "empoderada", ou seja, provida de poder, capacitada.
Outro ponto a refletir, conseqüência do anterior, é que se, por um lado, não partimos da realidade da comunidade envolvida, priorizando suas necessidades concretas, limitamos a participação da mesma nas ações de saúde; por outro lado o fato de discutirmos temas de conhecimento da comunidade, dando possibilidade para que eles definam e desenvolvam ações, juntamente com a equipe, para suprir estas necessidades, motiva o seu envolvimento no processo e potencializa a sua participação.

Em contrapartida a estas experiências positivas também pudemos vivenciar outras em que identificamos fatores que limitam a participação. Nas primeiras reuniões do conselho, nós, da equipe, achamos interessante discutir conceitos de conselho de saúde, função e papel dos conselheiros. Após algumas reuniões percebemos que a adesão e o interesse estavam diminuindo e que se continuássemos as reuniões desta forma, o Conselho esvaziaria. Assim, primeiramente, decidimos eleger um coordenador do conselho, que fosse membro da comunidade e em seguida realizamos o planejamento anual da equipe em conjunto com a comunidade, identificando alguns problemas, classificando-os por prioridades (da comunidade) e definindo ações em que equipe e comunidade envolvidas dessem encaminhamento. É importante destacar que mesmo antes da formação do conselho local, a parceria entre comunidade (associação de moradores) e equipe já existia, o que com o conselho intensificou-se, ampliou-se e ficou mais organizado. O resultado que observamos foi a satisfação e o comprometimento mútuo.

Vale ressaltar ainda que, existem alguns fatores observados no dia-a-dia e discutidos em reuniões periódicas com as outras equipes de saúde da família, nas quais expomos e trocamos experiências, que acabam limitando o processo. Em algumas equipes o número de famílias excede o preconizado pelo Ministério da Saúde (800 a 1000 famílias ou 2.500 a 4.500 pessoas cadastradas); não há integração entre os membros da equipe, existe competição entre os mesmos; ainda existem profissionais descomprometidos, pouco envolvidos 
com o processo; existem, também, erros de operacionalização do SUS ou das políticas adotadas pelo município, os quais muitas vezes deixam a comunidade insatisfeita e crendo que a equipe é responsável pelo fato. Algumas comunidades apresentam um envolvimento bastante limitado com a equipe e entre as pessoas que ali vivem, levando ao desconhecimento das ações por parte da comunidade, limitações e incompetências da equipe e, conseqüentemente, descontentamento da equipe e comunidade.

Na comunidade em que atuo no momento, particularmente, quando realizamos o planejamento anual, definimos algumas ações e conseqüentemente elegemos os responsáveis para viabilização das mesmas. Havia momentos em que alguns membros do conselho local se esquivavam das tarefas propostas. Certa vez, diante desta situação, um dos membros da equipe assumiu uma postura de cobrança, chamando-os a responsabilidade, como conseqüência na reunião seguinte apenas dois, dos oito representantes da comunidade, compareceram. Reconhecemos nossa precipitação e identificamos mais um fator limitante, a maneira de cobrar das pessoas as tarefas. Diante do ocorrido realizamos a reunião com os presentes (10) e definimos mais ações, nos comprometemos em avisar os demais sobre o que foi definido e verificar o que poderiam fazer para ajudar. Os presentes aprovaram a forma como (re)conduzimos a questão aprovaram o que ficou definido e envolveram-se nas ações propostas.

Outro fator limitante à participação, observado em nosso cotidiano é o uso do espaço comunitário para a autopromoção, identificado através de relatos, em reuniões com outras equipes do PSF e em nossas vivências. Este fato ficou evidente em uma reunião do Conselho de Saúde em que participou um vereador da comunidade. Durante a reunião ele ficou a frente das discussões, mobilizou-se para resolver um problema que foi levantado, definiu algumas ações e quando, em um momento, saiu para buscar alguns documentos, as pessoas, até então caladas, manifestaram-se; um dos conselheiros foi taxativo "nós não queremos ele aqui". Como a reunião estava sendo realizada na Unidade de Saúde, acharam que a participação deste vereador teria sido estimulada pela equipe de saúde. Explicamos aos presentes que o conselho estava aberto para quem tivesse interesse em participar das discussões, principalmente moradores desta comunidade e ao vereador informamos que as necessidades e as ações eram definidas e priorizadas após discussão e consenso geral entre os conselheiros e não apenas por um dos participantes. Este fato nos fez perceber que apesar da intenção ser aparentemente boa não conquistou a confiança dos presentes e anulou a participação naquele momento, explicitada pelo silêncio dos presentes durante o discurso do vereador.

Vale refletir, ainda, sobre a manifestação do conselheiro, que com indignação deixou claro que não queria ser excluído das decisões tomadas, que expor a sua opinião era importante e que não estava disposto a abrir mão deste espaço de participação conquistado.

Em nosso entendimento cabe aos profissionais de saúde e aos gestores, o compromisso de estarem atentos aos entraves descritos anteriormente, evitando que estas práticas se transformem em processos de dominação das classes, menos favorecidas.

A partir das vivências descritas, sintetizamos os seguintes fatores que potencializam e que limitam a participação:

Potencializadores: socialização dos problemas; a concretude das questões versus possibilidade de solução; profissionais considerando a população como co-gestora; trabalho com as potencialidades da comunidade na resolução dos problemas; profissionais capacitados, conhecedores do SUS, comprometidos e envolvidos com o serviço, interagindo com a comunidade; co-responsabilidade.

Limitantes: falta de escuta a comunidade, idéias pré-concebidas sobre quais sejam as necessidades da comunidade, problemas na estruturação dos PSF tais como: grande demanda; individualismo; falta de interação; desconhecimento 
e/ou não consideração das potencialidades da comunidade para melhoria da sua qualidade de vida; profissional com conhecimentos limitados sobre o SUS; uso dos espaços de participação para autopromoção (principalmente de políticos); comunidade pouco informada sobre o SUS e seus direitos.

O exposto ainda nos leva a refletir em como lidar com os fatores que limitam e potencializam estas práticas. Para tanto acreditamos que é fundamental que o profissional seja crítico, que perceba o contexto em que está inserido, que seja receptivo às mudanças e esteja envolvido (realmente). Quando falamos em dedicação plena ou exclusiva na ESF é porque ela realmente deve existir na prática. Percebemos, também, a necessidade de atualização do conhecimento profissional e que esta deve ser constante, de buscar formas de viabilizar o processo de trabalho junto às gerências e gestores e colaborar com idéias e conhecimentos obtidos em nossas vivências.

Enquanto profissionais de saúde da família, precisamos ter a clareza de que temos na própria ESF o estímulo às práticas de participação e de como elas contribuem para sua resolutividade. Sua contribuição está em prever a participação de toda a comunidade - em parceria com a Equipe de Saúde da Família - na identificação das causas dos problemas de saúde, na definição de prioridades, no acompanhamento da avaliação de todo trabalho feito. Sendo fundamental a atuação dos conselhos locais, igrejas e templos dos mais diferentes credos, associações, os vários tipos de organizações não governamentais (ONGs), clubes, entidades de todos os gêneros(7).

Este novo relacionamento com a comunidade, em que as forças sociais são bem vindas e requisitadas, é o que dá a possibilidade das metas estabelecidas pela equipe de saúde envolverem toda a comunidade(6). Ainda complementando, a ESF favorece o estabelecimento de novas relações, onde as partes atuantes são os sujeitos do processo ${ }^{(3)}$. Além de concordar com os autores citados, podemos afirmar, que o profissional necessita favorecer as relações entre comunidade/equipe, através dos
Conselhos de Saúde, grupos de educação em saúde, reuniões de associação, participação em eventos na comunidade (festas, torneios, feiras...), entre outros, fazendo com que a comunidade perceba que é parte integrante do processo. E isto se dá quando seu envolvimento é solicitado, pela equipe em todas as fases do processo, desde o planejamento, definição e execução de ações até sua avaliação, deixando que as idéias fluam e sejam discutidas, estudadas, evitando projetos prontos, ações pré-definidas.

\section{CONSIDERAÇÕES FINAIS}

A partir da reflexão sobre nossas experiências, constatamos que a principal mudança a ser efetuada em nossa prática é a de enfocar os usuários não como objetos de ação, mas como sujeitos políticos inseridos em um contexto, cercado de necessidades e possuidores de conhecimentos que lhe possibilitam contribuir para melhoria dos serviços.

O envolvimento e a integração com a comunidade rompem uma barreira, que há muito tempo existe, entre usuários e serviços de saúde. Para que isto se concretize é de suma importância que o profissional se comprometa, se envolva no processo, desperte a confiança da comunidade, transformando-a em sua aliada na busca de soluções para os problemas de saúde, estimulando-a a se tornar autônoma. A partir do momento em que este envolvimento e esta integração com a comunidade, acontece, rompem-se as barreiras que impedem a interação, abrindo-se um caminho para a troca mútua, contínua e integral.

Estas práticas de participação não estão somente ligadas ao usuário, mas a nossa necessária capacitação enquanto profissionais e cidadãos, que ainda não dominam este processo. O espaço, favorecido pelas equipes de saúde e conquistado pela comunidade, deve ser visto como estratégia para buscar benefícios ou resoluções através de um trabalho conjunto, valorizando a organização, a articulação dos envolvidos, o processo de discussão e o direito de manifestação destes grupos. 
Devemos ter o cuidado de evitar que a mobilização seja usada apenas para conseguir bens imediatos e/ou individuais, ou ainda transformar-se em um instrumento de manipulação destes grupos por pessoas que entendam este espaço como um meio de favorecer a autopromoção. Deve estar claro que participação não é só questão que concerne ao usuário, mas deve ser algo a ser aprendido e valorizado, também, por nós profissionais de saúde, que como eles não possuem a vivência plena da participação.

Com a intenção de facilitar a reflexão sobre nosso artigo desenvolvemos uma ilustração, onde agrupamos os fatores potencializadores e limitantes da participação, apresentando-os no quadro que segue:

\section{QUADRO 1 - FATORES POTENCIALIZADORES E LIMITANTES DA PARTICIPAÇÃO}

\begin{tabular}{|l|l|}
\hline \multicolumn{1}{|c|}{ Fatores potencializadores } & \multicolumn{1}{|c|}{ Fatores limitantes } \\
\hline $\begin{array}{l}\text { Profissional capacitado, } \\
\text { dedicado, conhecedor do } \\
\text { SUS, comprometido, } \\
\text { envolvido, interagindo com a } \\
\text { comunidade. }\end{array}$ & $\begin{array}{l}\text { Profissional com pouco } \\
\text { conhecimento sobre o SUS, } \\
\text { individualista e com } \\
\text { dificuldade de interagir. Falta } \\
\text { de atendimento humanizado e } \\
\text { de empatia decorrentes da } \\
\text { grande demanda. }\end{array}$ \\
\hline $\begin{array}{l}\text { Trabalhar com as } \\
\text { potencialidades da } \\
\text { comunidade na resolução dos } \\
\text { problemas. Envolver a } \\
\text { comunidade na realização das } \\
\text { ações programadas } \\
\text { juntamente com ela e } \\
\begin{array}{l}\text { apresentar os resultados. (co- } \\
\text { responsabilidade e co-gestão) }\end{array}\end{array}$ & $\begin{array}{l}\text { Desconhecer as } \\
\text { potencialidades da } \\
\text { comunidade. Pressionar a } \\
\text { participação comunitária com } \\
\text { açes pré-definidas apenas } \\
\text { pela equipe de saúde. }\end{array}$ \\
\hline $\begin{array}{l}\text { Minimizar a autopromoção } \\
\text { (política, inclusive) nos } \\
\text { espaços de participação. }\end{array}$ & $\begin{array}{l}\text { Permitir que os espaços de } \\
\text { participação sejam usados } \\
\text { para auto-promoção } \\
\text { (principalmente de políticos). }\end{array}$ \\
\hline
\end{tabular}

ABSTRACT: Although foreseen in law, the participation is not incorporating in our daily of attendance and it importance, a lot of times, it escapes from the perception of most of the professionals of health and of the own community. This article has the purpose of offering subsidies for the participative practices in health of the family, through the reflection about our experiences in a team of family health with the community's organized groups starting from what lifted the limiter factors and stimulant factors of those practices. It is waited that this reflection can contribute for the understanding and analysis of the experiences of participation, especially that verified in the pieces of health planning councils, that it comes if disseminating for the country, involving the community in the definition of the goals of the health. This way the favored integration for the community's insert in the definition of the actions of health breaks barriers that limit the participation process.

KEYWORDS: Health education; Consumer participation; Family health

RESUMEN: Aunque suministrar por en ley, la participación es no de añadir en pozo a nuestro cotidiano de asistencia $Y$ su cantidad de importancia, a menudo, él huir de la percepción de la mayoría de los profesionales de la salud $\mathrm{Y}$ de la comunidad. Esto artículo haber el un propósito de bulto subsidio de desempleo por la práctica participativa pozo a hasta su salud de la familia, vía la reflexión en el tema de nuestras experiencias pozo a una cuadrilla desde hasta su salud de la familia a lo largo de bandas organismo de la comunidad del dar gracias están hasta nosotros levantamiento el traje limitador Y estimulante de aquel práctica. Él espera en caso que dar gracias está hasta esto reflexión poseer sumar por la comprensión $Y$ análisis de las vivencias desde participación especialmente el un refrenado a los consejos de planificación en salud, dar gracias está hasta vienen en caso que diseminar por el país, abarcar la comunidad en la definición de las metas de hasta su salud. Por la integración favorecido pela inserción de la comunidad en la definición de las acciones desde hasta su salud brecha barrera dar gracias está hasta limitan el proceso de participación.

PALABRAS-CLAVE: Educación en salud; Participación comunitaria; Salud de la familia. 


\section{REFERÊNCIAS}

1 Cortes SMV. As origens da idéia de participação na área da saúde. Saúde em Debate 1996 Jun; 51: 30-37.

2 Midgley J. Community participation, social development and State. London: METHUEN; 1986.

3 Santana ML, Carmagnani MI. Programa de saúde da família no Brasil: um enfoque sobre seus pressupostos básicos, operacionalização e vantagens. Rev Soc Saúde 2001 Jan; 10: 33-53.

4 Demo P. Participação é conquista. 3. ed. São Paulo: Cortez; 1996.
5 Souza ML. Desenvolvimento de comunidade e participação: a participação componente conceitual do DC. 2. ed. São Paulo: Cortez; 1990.

6 Wendhausen ALP, Saupe R. Concepções de educação em saúde e a Estratégia de Saúde da Família. Rev. Texto Contexto Enferm 2003 Jan-Mar; 12: 17-25.

7 Ministério da Saúde (BR). Secretaria de Assistência à Saúde. Departamento de Atenção Básica (Brasília). Guia prático do Programa de Saúde da Família. Brasília; 2001.

Recebido em 21/01/2003

Aceito em 07/05/2003 